\title{
Corrigendum: Assessing the Role of Collective Efficacy Beliefs During Participative Occupational Health Interventions
}

\author{
Marco Kuchenbaur* and Richard Peter \\ Institute of the History, Philosophy and Ethics of Medicine, Ulm University, Ulm, Germany
}

OPEN ACCESS

Approved by:

Frontiers Editorial Office Frontiers Media SA, Switzerland

${ }^{*}$ Correspondence:

Marco Kuchenbaur marco.kuchenbaur@uni-ulm.de

Specialty section

This article was submitted to Occupational Health and Safety,

a section of the journal

Frontiers in Public Health

Received: 25 November 2021 Accepted: 26 November 2021

Published: 16 December 2021

Citation:

Kuchenbaur M and Peter R (2021)

Corrigendum: Assessing the Role of Collective Efficacy Beliefs During Participative Occupational Health

Interventions.

Front. Public Health 9:822431. doi: 10.3389/fpubh.2021.822431
Keywords: participative intervention, collective efficacy beliefs, process evaluation, occupational health, questionnaire

\section{A Corrigendum on}

Assessing the Role of Collective Efficacy Beliefs During Participative Occupational Health Interventions

by Kuchenbaur, M., and Peter, R. (2021). Front. Public Health 9:797838. doi: 10.3389/fpubh.2021.797838

In the original article, there was a mistake in Figure 2 as published, due to the upload of a broken .eps file in the pursuit of a less pixelated rendering of figure 2. The corrected Figure 2 appears below.

The authors apologize for this error and state that this does not change the scientific conclusions of the article in any way. The original article has been updated.

Publisher's Note: All claims expressed in this article are solely those of the authors and do not necessarily represent those of their affiliated organizations, or those of the publisher, the editors and the reviewers. Any product that may be evaluated in this article, or claim that may be made by its manufacturer, is not guaranteed or endorsed by the publisher.

Copyright (๑) 2021 Kuchenbaur and Peter. This is an open-access article distributed under the terms of the Creative Commons Attribution License (CC BY). The use, distribution or reproduction in other forums is permitted, provided the original author(s) and the copyright owner(s) are credited and that the original publication in this journal is cited, in accordance with accepted academic practice. No use, distribution or reproduction is permitted which does not comply with these terms. 


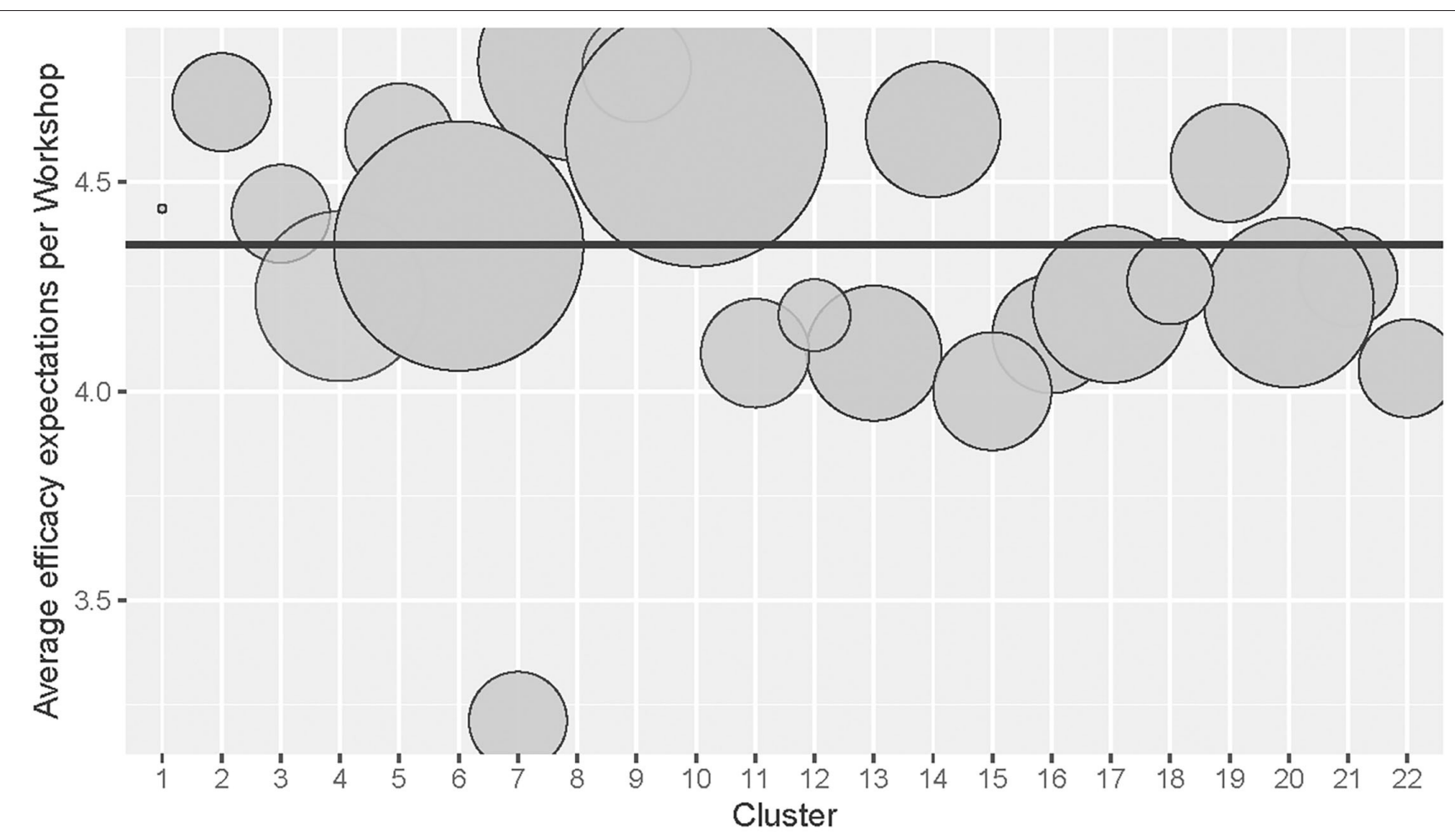

Number of interventional measures

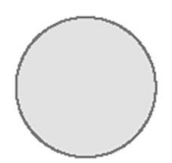
10

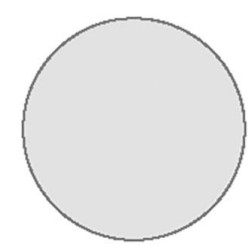
20

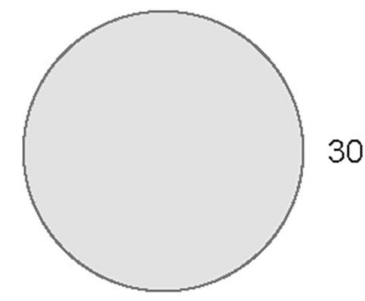

FIGURE 2 | Number of interventional measures across workshop groups (Cluster). 